\title{
M-learning in Foreign Language Learning
}

\author{
Bianqi Sun \\ Department of Foreign Language \\ Beijing Institute of Graphic Communication \\ Beijing, China
}

\author{
Hou Shu \\ School of Electronic Engineering \\ Beijing Institute of Graphic Communication \\ Beijing, China
}

\begin{abstract}
Teachers nowadays have much more roles compared to that of prE-internet period. As an English teacher, how to help and support students to achieve the maximum learning result are always his top concerns. The purpose of this paper is to demonstrate that MobilE-Assisted Language Learning (MALL) in general and smartphone usage in particular, is capable of supporting applications based on a variety of learning theories, especially constructivism and methodological approaches. The paper aims at introducing the experience of language teaching and learning through the means of social networking devices, providing some practical solutions to the problems existing in Chinese foreign language teaching of higher education, sharing the experience, observation, concrete approaches in the course of College English and ESP course for non-English-major postgraduate. It is hoped that the strategies employed in the course of language instruction can offer some constructive insights for English teachers and students.
\end{abstract}

Keywords-M-learning; mobile device; smartphone; mobility; language learning; $M A L L$

\section{INTRODUCTION}

English language teaching has been severely criticized by all walks of people due to the ever-increasing social demand and the relatively poor status quo. Teachers feel obliged to improve the situation by changing the traditional mode of teaching with the help of modern technology. Modern mobile tools, Web 2.0 technology and the internet have not only brought great convenience to our day-to-day life, but also updated the traditional means of language teaching and learning, which offer a new platform for students' communication, discussion and experience sharing, serving as the source of information. 3M-Learning (multi-modality, multi-media, and multi-environment) makes it a continuous process with no limits to time, space and regular classroom, which immensely extends the educational dimensions for language learners.

In China, the last several decades have witnessed a steady and rapid improvement in computer assisted language learning (CALL) materials from very simple text-related tasks and simple exercises to highly sophisticated interactive tools and multimedia applications. It is widely accepted that the new technology has led to new perspectives in teaching, and language teaching is among the fields which have undergone dramatic changes as a result of rapid improvement in technology.
With the emergence and rapid improvement of small, portable notebook computers, for instance, the concept of "mobile learning" has aroused the interest of educators and gained great popularity among college students. Ever-updating technologies, developments in information technologies and telecommunication have inspired people to make use of this "anytime" and "anywhere" technology in language teaching. Many scholars (Meskill 2010; Pegrum 2014; Evans 2008; Kukulska-Hulme 2009) have studied the use of mobile devices in teaching and learning, and put forward instructive suggestions of effective language acquisition. This paper further explores the in-depth use of mobile devices and clarifies some concepts in this field. The benefits, limitations and practical approaches are discussed.

\section{DEFINING CONSTRUCTIVISM}

Traditional way of language learning has been changing with the improvement of technology, focusing on the interaction and autonomy of the learners. For foreign language learners, lack of authentic environment is always the main reason for "deaf and dumb" English. Communication with the native speakers is, with no doubt, a big problem. Though the teachers try to make every student open their mouth in English class, yet because of the huge size of language class, each student barely has one chance to speak in 50-minutE-long class. This explains why the emergence of mobile devices has inspired educators, scholars, and investors so much as to explore uses of those devices in language teaching. As a supplementary tool, incorporated with the internet, mobile devices (mainly smartphone) become more powerful than ever. They broaden the concept of "class", making prE-class, inclass, post-class blended together, thus creating an everexisting virtual environment or platform for students to communicate, practice, and improve academically. This exactly conforms to the theory of constructivism, which emphasizes the knowledge construction in certain social context collectively or individually.

Constructivism in education emerged after the behaviorist movement as a prevailing and refreshing view of learning that focuses on the active learners within the teaching-learning process. In higher education, it is highly advocated that classes should be student-centered, and students play a dominant role in the whole process of teaching and learning. The advent of modern social tools makes it possible for students to teach themselves and design their pace of learning according to certain pace. Accordingly, teachers' roles have changed to directors, facilitators, guides, helpers. 
As Gail Jones (2002) put it, "The constructivist focus on the social context and larger community of learners has resulted in a major shift away from individually-based instruction to instruction that incorporates and embeds teaching within the larger community of peers, younger students, as well as those who are older." Social constructivism and educational constructivism (including theories of learning and pedagogy) have had the greatest impact on instruction and curriculum design because they seem to be the most conducive to integration into current educational approaches.

"It is assumed that learners have to construct their own knowledge - individually and collectively. Each learner has a tool kit of concepts and skills with which he or she must construct knowledge to solve problems presented by the environment. The role of the community-other learners and teacher-is to provide the setting, pose the challenges, and offer the support that will encourage mathematical construction." (Davis, Maher, Noddings, 1990, p. 3) (Quoted from Gail Jones (2002))

"Constructivism is not a theory about teaching... it is a theory about knowledge and learning... the theory defines knowledge as temporary, developmental, socially and culturally mediated, and thus, nonobjective." (Brooks \& Brooks, 1993, p. vii) "(Quoted from Gail Jones (2002))

Although Piaget's theories tended to focus primarily on the development of the individual while ignoring the greater sociocultural context, the roots of constructivism are clearly present in Piaget's focus on the active role of the individual in learning: "... all knowledge is tied to action, and knowing an object or an event is to use it by assimilating it to an action scheme..." Piaget, 1967, pp. 14-15).

From the above definitions of constructivism, we see the features of M-learning are suited to the theory, in which students construct their language knowledge by self-controlled automatic learning in the context. The flexibility, continuity, and autonomy of M-learning all contribute to the knowledge construction.

\section{WHAT IS M-LEARNING?}

Efforts to develop MobilE-Assisted Language Learning (MALL) programs have been going on now for some years, based on hand-held technologies: MP3 players, MP4 player, Personal Digital Assistants (PDA), smartphones. The iPod and iPad offer audio playback and recording functions. The PDA, or palM-top computer, provides basic computer programming capability and access to the Internet. The smartphone technology has pushed the hand-held devices to the level of regular computer, only smaller in size. The capacity of memory has amounted to over $100 \mathrm{G}$, and installation of software makes it convenient for language learners to develop the basic language skills.

According to my observation and interviews with students, their attitude towards E-learning is affirmative. Students overwhelmingly view the use of mobile technology very favorably owing to its "anywhere, anytime" convenience. Positive student attitudes towards the use of mobile technology have provided a major impetus to implement MALL.
Emerging mobile technologies and new applications facilitate communication, collaboration, sharing and learning in settings unbounded by time and space. As to the definition of M-learning, there are different interpretations towards what M-learning is, depending on the different perspectives from which M-learning is viewed. Basically, we may sum up as the follows:

- M-learning is considered as a technological extension of E-learning originated in the 1980s and the CALL of 1990s. It is the result of the technological development;

- M-learning multiplied the diversified way or style of learning, enriching the connotation of regular classroom learning, offering a different perspective;

- M-learning is techno-centered, which makes the learning happen at any time or in any place. Accessibility becomes a convenient and timE-effective act;

- M-learning is learner-centered, which focuses on the separate needs of individual students. Learner-centered activities can only be designed and implemented in blended lecture of the virtual world. With the internet, the portable devices are wirelessly connected and create a global community, and the social networking facilitates the interaction and experience sharing.

\section{MobiLE DeVICES AND APPS FOR LANGUAGE LEARNING}

We define applications, abbreviated to apps, as software programs for a computer or phone operating system. According to Wikipedia ${ }^{1}$, "A mobile app is a computer program designed to run on mobile devices such as smartphones and tablet computers. Most such devices are sold with several apps bundled as prE-installed software, such as a web browser, email client, calendar, mapping program, and an app for buying music or other media or more apps. Some prEinstalled apps can be removed by an ordinary uninstall process, thus leaving more storage space for desired ones. Where the software does not allow this, some devices can be rooted to eliminate the undesired apps."

In China, English as a required course is regarded as one of the three most important courses along with Math and Chinese language before college. In higher education, it becomes more important because many universities connect the passage of Band IV national English examination with the grant of diploma. And diversified demands of furthering their studies cannot be fulfilled without proficient English. Thus numerous Apps for English learning have been commercially developed, which greatly facilitate and create a virtual world of language. Moreover, other social networking software is also flexibly used for language learning purpose. For example, the most popular social networking WeChat, with over 0.6 billion users in China, is becoming an indispensable tool connecting students and teachers. The sister companion software is QQ, which is also developed by Tencent corporation. The latter can both be installed in smartphones as well as computers, which makes it more convenient to send and receive large files.

\footnotetext{
${ }^{1}$ https://en.wikipedia.org/wiki/Mobile_app
} 
According to a survey, over $90 \%$ and $70 \%$ college smartphone users have installed the software respectively.

The following Apps are quite popular among language learners in China:

English Radio

BBC NEWS

\section{YAHOO NEWS DIGEST}

Voice Tube

VOA 慢速英语 (VOA special English)

VOA 每日英语 (VOA everyday English)

VOA 英语网 (VOA English Learning.)

蜻蜓 FM (Qingtingfm, an APP of online radio station, http://www.qingting.fm/ )

喜马拉雅 FM (ximalaya, an APP of online radio station, http://www.ximalaya.com)

百词斩 (Baicizhan, an vocabulary learning app.)

乐词 (Happy Word, an vocabulary learning app.)

奇速英语 (Instant English)

疯狂闯关背单词 (Crazy Vocabulary Learning)

网易有道词典 (Youdao Dictionary, also translation software)

沪江听力酷 (Hujiang Foreign Language Listening)

英语流利说 (Fluent Spoken English)

Actually I can make the list much longer with ease. What is more important is that you can always find the right App for language skills training: listening, speaking, reading, writing and translation. The online sources of material are totally free, like some of the free online MOOC courses.

Countless authentic materials and free download make it valuable for foreign language learners. The downloaded offline material can be replayed and reviewed again and again. What's more important, free exchange of the learning material constitutes a rich customized source of information.

China witnessed an accelerating speed of smartphone sales in the past decade. And in the future, the increase rate will become stable, because the affordability is no longer a problem, and fact is every college student has one smartphone, and it is not rare that some of them have more than one, plus other mobile devices. Another thing I need to point out is that the large screen smartphone accounts for a larger and larger market share, that tablet computing devices, Ipad, Ipod, PDA, mp4 players etc. are seeing a gradual decline in sales market.

\section{Features of Mobile Pedagogy}

Learning is mobile, situated, contingent, context-aware, and authentic. Learning happens both formally and informally, in and between classrooms, homes, transport and other spaces, and in communities extending beyond learners' immediate physical environments and networks. In this way the mobile pedagogy provides the potential for the students to be plunged in the environment of social context. It extends the physical space and learning hours, thereby students have better conditions to do the prE-class and post-class activities. Classrooms may be 'flipped', or blended, combining facE-toface learning with online distance learning.

In the class hours, the main task for the teacher is to check and guide. Teachers may ask learners to record language practice activities in class and use these recordings collaboratively to help each other correct errors, and to research and reference grammar rules based on common problem areas. In a way, the role of a teacher becomes less important than that of the traditional classroom.

In my ESP course of Chinese Printing, at the very beginning of a new semester, the students are required to form eight groups (7-8 members each). For each teaching unit, all the members of a given group will do the presentation, either in PPT or play the recorded videos or conversation acting-out. Through the collaboration, every student contrives to do his/her best, because I grade each group a score as a whole. In the presentation the cooperative efforts are clearly seen. Compared with the teacher dominated class, all students feel that they are the actors instead of audience. The devotion and enthusiasm in their production of their videotaping assignment give them a sense of accomplishment. The extracurricular preparation and learning lengthen their learning time, developing their ability of organization and cooperation.

Various activities are conducted according to different contents of each unit. But basically, I require the students to the following thing:

- Ask students to act out the conversations and the relevant verbal parts by video recording and editing, and post it on the public space of the class in WeChat or QQ for their peers to watch and comment.

- Use the smartphone as a tape/video recorder to convert the written script into sound files, so that others can identify the mispronunciations and improper intonations. The mutual evaluation and error correction improve the ability of speaking, especially for those who dare not deliver a speech in the presence of class.

Smartphones are becoming popular and the use of the mobile communication devices goes beyond the communication role. More than ever, smartphone serves as a mobile platform with easy accessibility to the internet. The technology of web 2.0 further promotes the smartphone to the maximum. Almost all tasks done on the computer can be done on smartphones. In higher education of China, smartphones have been widely used to store and retrieve information as Ebooks, video clips, all OFFICE files. Countless free English learning apps are installed, which makes it a source of information and training center. In China almost all smartphones install the social network software WeChat and QQ (by Tencent Corporation), which closely connect all its users and offers the largest platform for communication of daily affairs. In some university the teachers and students set up different groups for instant academic exchange. Teachers 
also use it to assign tasks, giving notices, and other studyrelated affairs. The social networking community like WeChat or QQ shortened the physical and spiritual distance between teachers and students. Teachers are almost available at any time. Offline upload and storage make the material accessible to anybody in the group when logged in.

Free installation of E-dictionaries make the vocabulary learning convenient, students learn the vocabulary with the right pronunciation, synonym, antonym, origin in the right sentence examples. Whatever new words they consult, there is a history of record, and the consulted words spontaneously go to the NEW WORDS, which can be reviewed conveniently in the later time. To make the vocabulary-learning interesting, the developers of the apps design the activity in the form of games, recording your score and memory curves.

Actually, you can search for some information regarding your assignments, like the main points, and then you can develop your ideas and use them at home. But plagiarism is strictly prohibited. There is plagiarism checker software to verify the originality of the written work. One student once said, "I generally use my smartphone to take notes of whatever I see on the board, or take photos of diagrams and PPT." Students are encouraged to send their written paper through the smartphone E-mailbox at any time, and online chatting through WeChat or QQ are becoming a routine communication between teacher and students.

\section{BENEFITS OF M-LEARNING}

As a supplement for the traditional education, M-learning provides a new platform and broadens the regular perspective of learning. Cheung summarizes the benefits of M-learning as follows:

"In brief, mobile learning transforms the learning process and changes the ways of learning, creates new opportunities beyond the traditional classroom, offers flexibility and mobility in learning, expands learning experience in terms of time and place, facilitates communications and interactions among teachers, students and course administrators as well as encourages the mode of collaborative learning" (Cheung 2012: 90).

Since its emergence as an extension of E-Learning at the beginning of the 2000s, MALL (Mobile assisted language learning) devices and applications have been intensively studied in many studies. Most of these studies have either supported or disclaimed the use of MALL as a learning material in educational settings.

For those studies which are in favor of the use of Mlearning as a necessary means, they maintain the following points.

- Contingent learning and teaching. E-learning breaks the confinement of physical four-wall classrooms, and this unique feature of mobile devices results in many other advantages. For language learners, the small bits of time can be well utilized compared with the learning of other subjects of science and engineering. Students claim that skills like vocabulary learning, listening, pag E-browsing are not limited to the length of time.

- Ubiquity of mobile devices. Another reason that makes MALL devices advantageous is that they are highly accessible and there is a very widespread ownership of certain mobile devices like smartphones, wireless laptops, and media players (ITU, 2009). Portability and widespread ownership concepts together correspond to the ubiquity of MALL devices, which has been a useful concept to define mobile learning and MALL.

- Affordability of mobile devices. Smartphones, first of all, free learners from place and time limitations and this is a highly motivating situation for the students. Modern technology makes smartphones as powerful as PCs. What's more, some of the smartphones can be as cheap as less than 100 yuan RMB (about US\$16). More sophisticated smartphones and free use of internet on campus connect students to the internet anytime and anywhere.

- Collaborative learning. Where learners work on a shared project on the same platform, and the learning outcomes build on their collective rather than individual efforts. In the course of their work, teachers are ready to give them a hand at any time. In China, WeChat and QQ are two social networking platforms people use the most, and students set up countless groups for different purposes.

- Accessibility of Apps. Easy access to the language learning apps greatly facilitates the students. The variety of apps for different language skill training brings great convenience to the study, and makes a good balance of the five basic skills: listening, speaking, reading, writing, translation.

Various advantages and potential benefit of MALL and the use of mobile devices in foreign language learning have been discussed. Despite the abundance of benefits of using MALL as a supplementary learning material, there have also been claims about the drawbacks and difficulties of using MALL in foreign language learning or learning in general.

\section{LIMITATIONS OF MOBILE DEVICES IN LANGUAGE CLASS}

Besides benefits, previous studies showed some limitations as well.

- Distraction. While in a language class, learners need time and space to focus, think and learn without distractions. Language learning is a tedious and painstaking work, and surfing the internet is thrilling and exciting. Improper use of smartphone in class could be various: playing games, reading novels, browsing webpages of news, watching online matches, contacting with outsiders, etc. My usual way to control the improper use of smartphone in class is to ask them to turn off.

- Inconvenience. Some files cannot be well displayed because of small screen, low resolution, inadequate 
memory etc. And compatibility with computer software is still a problem. Inconvenience can be regarded as the cost of mobility. With the passage of time, technology could solve some of the problems, but large screen size and portability seem to be contradictory.

- Improper psychological dependence. There are two sides to everything. Easy access to answer can discourage students' concentration and devotion. Some students think smartphones offer a shortcut in language learning, so they often take photographs of the lectures and store the information in the smartphones rather than spend time to memorize them in the brain. In writing, some students seem unable to finish their written work without using smartphone for consulting.

\section{CONCLUSION}

This paper argues that mobile devices with enhanced capabilities offer new learning possibilities and perspectives which meet the needs and demands of language learners, and clarifies some of the definitions concerning M-learning. Advantages and limitations of M-learning are discussed. It has to be noted that the technical limitations can be solved with the development of multimedia technology, but improper use of mobile devices seem to become a serious problem in the meantime. In extreme cases, the advantages of smartphones in the class can be outweighed by the inevitable distractions like video-watching, music-listening, social chatting, etc. So sometimes it is a good way to ask the students to turn off smartphones or turn to flight mode. Without doubt, frequent informal practice and out-class language practice can be done easily on mobile devices, and those tools create the most favorable environment. From a blended learning point of view, mobile devices were found to provide a "cost-efficient alternative" to traditional E-learning tools, such as desktop laboratories and pods of laptops, as they are becoming "more powerful, portable, affordable and accessible" (Churches et al. 2011: xiv).

The ubiquity of mobile devices on college campuses has become a fact and greatly influenced the lives of bother teachers and students. How to further explore their educational functions is a problem faced by educators. It is clear that teachers' role in education has changed or even weakened in digital era. I personally believe that focus of the researchers should be put on "mobility" and "learner-centeredness." Afroza Akhter Tina (2016) pointed out, "Although many successful implementation examples of teaching and learning with mobile devices in tertiary education were identified, it was noted that a large majority of higher educators have not yet widely explored the wealth of M-learning possibilities in depth."

As discussed above, teacher-centered, vocabulary and grammar tutorial programs have proven well suited to the mobile virtual environment. Constructivist, collaborative, learner-centered pedagogical approaches have also inspired a range of MALL applications that include vocabulary acquisition, listening, speaking, reading, and translation activities as well as collaborative learner-learner interactions. Given the ubiquity of smartphone worldwide, the ever improving functionality of these devices and their pedagogical adaptability, MALL is bound to be a necessity to provide support for foreign language instruction, for which language teachers need to be preparing now

\section{ACKNOWLEDGMENT}

This research is supported by the Science \& Technology Research Common Program of Beijing Municipal Commission of Education (No. KM201510015011); the Discipline Construction and Postgraduate Education Program of Beijing Municipal Commission of Education (No. 21090116020); the Program for Science Development and Foreign Language Education of Guangxi Academy of Social Sciences (No. GXSLXM-15-05); the Major Teaching \& Reform Program of Beijing Institute of Graphic Communication (No. 22150115033).

\section{REFERENCES}

[1] Afroza Akhter Tina(2016). Bangladesh Research Foundation Journal [ISSN 2224-8404 (Print), 2305-1566 (Online)], Vol. 5, No.1, February 2016 Enhancing English Language Learning through Mobile Technology: A Bangladeshi Perspective.

[2] Brooks, J., \& Brooks, M. (1993). The case for the constructivist classrooms. Alexandria, Va: ASCD.

[3] Cheung, S.K.S (2012). A study on the use of mobile devices for distance learning. In S.K.S. Cheung(Ed.), Hybrid Learning: Lecture Notes in Computer Science (pp.89-98). Berlin Heidelberg: Springer.

[4] Churches, A. \& Dickens, H. (2011). Apps for learning: 40 best iPad, iPod Touch/iPhone apps for high school classrooms. The 21st century fluency series (1st edition). Thousand Oaks, California: SAGE Publications.

[5] Davis, R., Maher, C., Noddings, N. (1990). Introduction: Constructivist views on the teaching and learning of mathematics. In R. Davis, C. Maher, \& N. Noddings (Eds.) Constructivist views on the teaching and learning of mathematics (pp.7-18).

[6] Evans, E. (2008). The effectiveness of M-learning in the form of podcast revision lectures in higher education. Computers \& Education, 50, 491-498.

[7] Gail Jones, M., Laura Brader-Araje (2002). The Impact of Constructivism on Education: Language Discourse, and Meaning American Communication Journal Volume 5, Issue 3.

[8] ITU, (2009). The World in 2009: ICT Facts and Figures. Report retrieved November 3, 2009 from http://www.itu.int/ITUD/ict/material/Telecom09_flyer.pdf

[9] Jack Burston (2011). Visited on June 15, 2016 from https://www.researchgate.net/publication/258962305_Exploiting_the_p edagogical_potential_of_MALL

[10] Kim Bracke (2013). Apps for mobile language learning: A market research into English language learning apps. HoGent Geassocieerde Faculteit Toegepaste Taalkunde.

[11] Kukulska-Hulme, A. (2009). Will mobile learning change language learning? TheJournal of the European Association for Computer Assisted Language Learning, 21(2), 157-165.

[12] Kukulska-Hulme, Agnes; Norris, Lucy and Donohue, Jim (2015). Mobile pedagogy for English language teaching: a guide for teachers. British Council 2015, London.

[13] Meskill, C and Anthony, N (2010). Teaching Languages Online. Bristol: Multilingual Matters.

[14] Pegrum, M (2014). Mobile Learning: Languages, Literacies and Cultures Basingstoke: Palgrave Macmilla.

[15] Piaget, J. (1967). Biologie et connaissance (Biology and knowledge), Paris, Gallimard. 